Sousa H.S., Branco, J. M., Lourenço, P. B. (2014) Characterization of cross sections from old chestnut beams weakened by decay. International Journal of Architectural Heritage 8(3). pp 436-451. (doi.org/10.1080/15583058.2013.826303)

\title{
Characterization of cross sections from old chestnut beams weakened by decay
}

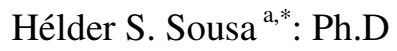 \\ Jorge M. Branco ${ }^{\text {a }}$ : Assistant Professor \\ Paulo B. Lourenço ${ }^{\text {a }}$ Full Professor \\ ${ }^{a}$ Department of Civil Engineering, ISISE, University of Minho, Portugal \\ * corresponding author: \\ ISISE, University of Minho, Department of Civil Engineering, Azurém, \\ 4800-058 Guimarães, Portugal \\ e-mail: hssousa@ civil.uminho.pt; Tel: +351 253510200; Fax: +351 253510217
}

\begin{abstract}
This work aims to experimentally assess the material properties of old chestnut (Castanea sativa Mill.) cross sections weakened by decay. Specimens were taken from critical zones of twenty floor beams, mostly corresponding to their ending parts, in contact with granite masonry walls. These specimens were compared with clear wood specimens taken from nondecayed parts . The experimental campaign comprised of visual inspection, non-destructive testing (ultra-sound, impact penetration and drilling resistance tests) and uniaxial compression tests, parallel to the grain. Pin penetration test evidenced a depth of penetration $36 \%$ higher for decayed specimens compared to non-decayed specimens, proving the loss of capacity in the superficial decayed layer. The results of decayed specimens exhibited a decrease of approximately $30 \%$ in the compressive strength parallel to the grain. A reduction of approximately $5 \%$ was found for the dynamic and elastic moduli. The coefficients of variation for decayed specimens are significantly higher than for sound specimens. Different decay models are considered and compared aiming at analyzing decay evolution along time and determining the decrease of load bearing cross section. Finally, the results were used to calibrate a bi-parametrical decay model for above ground timber structures, considering a linear relation between time and decay depth.
\end{abstract}

KEYWORDS: timber structures, weakened sections, decay, experimental evaluation, compression parallel to grain 


\section{INTRODUCTION}

The effects of ageing and decay must be considered in historical constructions since the exposure of timber elements to the environment and to pathological agents leads to a reduction of the mechanical properties along time. Considering the ageing process and the usual life expectance of structural timber, it is possible to state that load history and time do not affect significantly the mechanical and physical properties of sound wood in compression when decay is not present and creep is not considered (Lourenço et al., 2007). Decay, on the other hand, has an important effect in the mechanical properties of wood even in early stages of development, such as in incipient stages of decay by fungal attack. Incipient decay may be considered as discoloration or a mottled appearance, without obvious changes in naked eye appearance and microscopic examination. Incipient decay, below about $10 \%$ weight loss, might be difficult to identify with certainty (Wilcox, 1968). Despite this fact, it can cause significant reduction in wood strength. For example, compression and shear parallel to the grain can be reduced up to $20 \%$ before decay is visually identified, with bending strength being even more sensitive (Wilcox, 1978). And the strength loss due to incipient decay in softwood species can reach up to 80\% (see Table 1) (Stalnaker and Harris, 2002). Fungal decay, in particular, produces a loss on toughness and bending strength (Wilcox, 1978). As decay is often present in existing buildings, it should be characterized and its consequences need to be assessed.

Table 1: Percentage loss of mechanical properties due to incipient decay in early wood (Stalnaker and Harris, 2002)

\begin{tabular}{cc}
\hline Strength property & Average strength loss $(\%)$ \\
\hline Static bending & 70 \\
Impact bending & 80 \\
Modulus of elasticity & 70 \\
Compression parallel to grain & 45 \\
Tension parallel to grain & 60 \\
Compression perpendicular to grain & 60 \\
Shear & 20 \\
\hline
\end{tabular}

In Carll and Highley (1999), it was found that the evolution between various stages of decay was quantitatively accompanied by the cell wall thinning, even for early stages of brown rot fungus attack. Yang et al. (2000) mentions that it is difficult to determine the presence and the stage of decay from density alone, due to the natural variability in wood density and lack of information on density loss at various stages of decay. Here, it is also stated that the increase of 
decay has little effect on the elastic modulus in static bending (MoE). However, studies using X-ray microdensitometry (Bucur et al., 1997 and Macchioni et al., 2007), for the determination of the kinetics of wood degradation by fungi, have evidenced the correlation between density decrease and mass loss in different stages of fungal wood degradation.

Fungal growth is assumed to take place especially for moisture contents over 20\% (Zabel and Morrell, 1992), which is also a favorable condition for insect attack (Ross et al., 2004). The presence of unwanted moisture in a structure (structural dampness) may be caused by water intrusion from outside or condensation from within the structure. In the case of buildings, a significant proportion of damp problems are related to condensation, rain penetration or rising damp (Trotman et al. 2004). In fact, $90 \%$ of the decay observed in buildings may be associated with water leakage (Viitanen and Ritschkoff, 1991), or also frequently from condensation within the external walls that is absorbed by wood, and biological attack is the most significant damage source in heritage timber structures. Insect and fungal attack lead to the destruction of wood constituents responsible for the structural strength and damage progressively spread to unaffected wood if no action is taken. Thus, the continued or new use of a building with structural timber must include an inspection of biological attack and, if found even in small percentages, must include also an assessment of its significance and influence to the mechanical properties of the element itself and neighboring elements (Beckmann and Bowles, 2004). The results of a diagnostic survey will, therefore, influence the design of possible structural restorations and of maintenance operations (Macchioni et al., 2012).

This work aims to characterize the mechanical properties of sections weakened by decay in old chestnut (Castanea sativa Mill.) floor beams. Chestnut is a very common wood species in historical construction in the North of Portugal (Southwest Europe) mainly due to its availability in the past, its good mechanical properties and its durability. The decay stage in the weakened sections of the beams was visually detectable. Non-destructive and destructive tests were made in the weakened sections for comparison with sections without decay. A comparison between parameters obtained by different decay evolution models is also addressed, aiming at the assessment of the loss in load bearing cross sections through time. Non-destructive test results are used to calibrate a specific decay model for the present case study.

\section{BEAM CHARACTERIZATION}

\subsection{Samples and testing methodology}

The tested structural elements correspond to twenty old chestnut (Castanea sativa Mill.) beams retrieved from a construction site located in Northern Portugal. The structural floor beams were supported, in both endings, by granite masonry walls. The elements are about 100 years old 
(early $20^{\text {th }}$ century construction) and were removed in the rehabilitation process of the building. The length of the elements varied between $4 \mathrm{~m}$ to $6 \mathrm{~m}$, with a mean value of $5.32 \mathrm{~m}$ and coefficient of variation $(\mathrm{CoV})$ of $11.8 \%$. As inspection to the elements was only possible after removal from the building, and no reliable information about the length of the supporting portion of the beams was possible. The floor consisted in a traditional structural solution with wooden planks connected to the top surface of the beams by iron nails that due to its age were corroded and started to affect the nearby wood.

Initially (Phase 1), the beams were visually inspected using Italian norms (UNI 11035-2:2003, UNI 11119:2004) and critical sections were considered depending on the applied stresses combined with defects distribution and quantity. Moreover, sections where decay was present were identified and classified according to different levels of decay appearance, accounting for the aim to characterize sections weakened by decay. Subsequently (Phases 2 and 3), the study of the elements was divided into decayed sections and non-decayed parts (Figure 1).

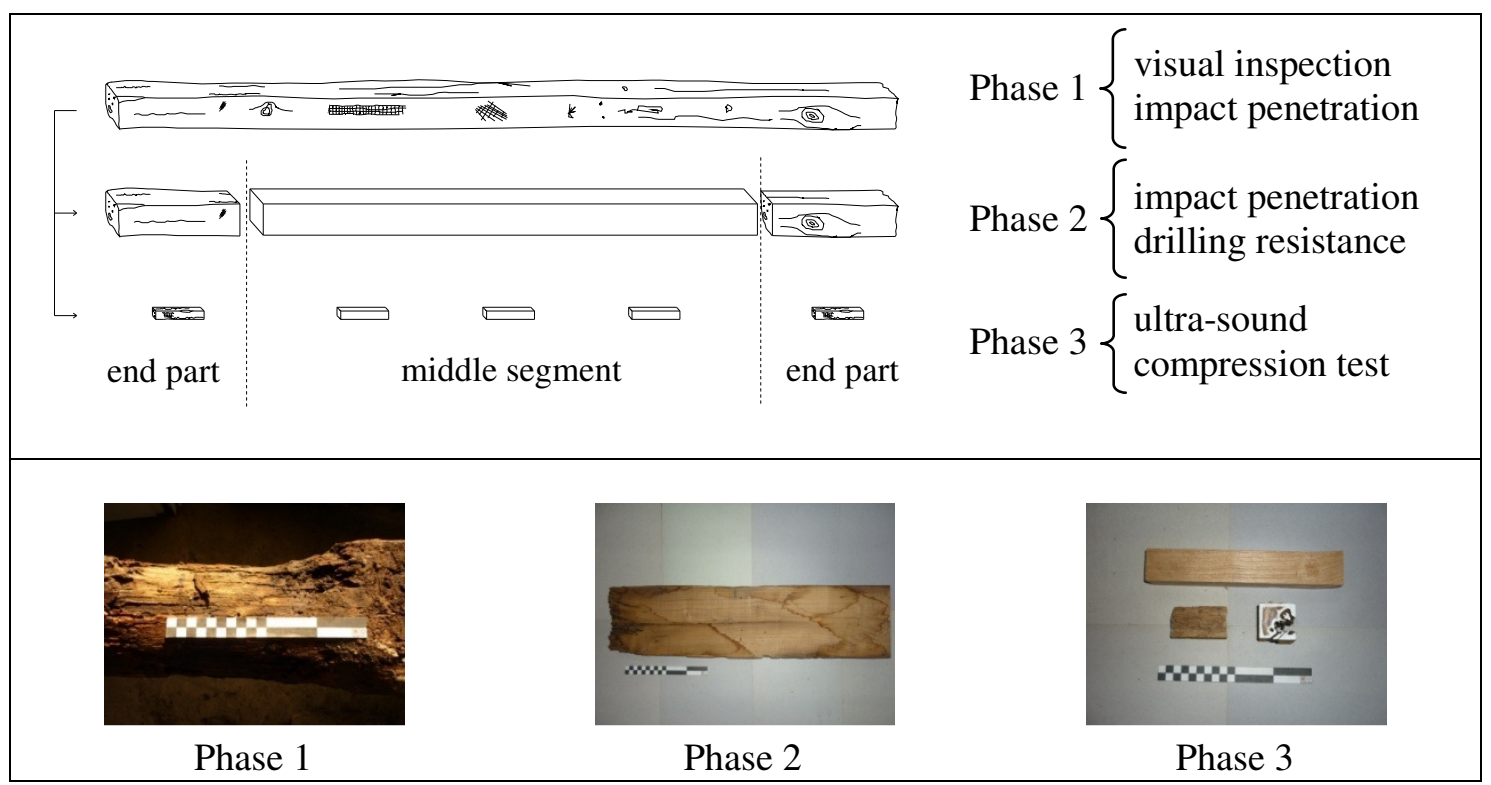

Figure 1: Test sequence and samples: Phase 1 with the full beam; Phase 2 with the end parts of severely decayed wood and middle segment of lightly decayed wood; Phase 3 with small sound specimens.

The decayed sections were mainly found in the ending part of the beams that were in contact with the masonry walls and were exposed to higher moisture contents. The reference samples were obtained by removing the external layer of decay, taking small clear specimens from the non-decayed interior of the beams. In both cases, the sections were tested by impact penetration and drilling resistance tests and samples were taken in order to perform ultra-sound 
measurements and compression parallel to grain tests according to EN 408:2003. Regarding the compression tests, three reference samples were taken from the middle segments for each beam. For the end part of the beams that presented decay, one sample was taken if it could provide two adequate parallel surfaces for testing. It is noted that the values of compression strength parallel to grain from decay specimens were obtained using the cross section area of the failed section of each sample. The number of specimens and measurements for each test campaign phase are given in Table 2.

Table 2: Number of specimens and measurements for each experimental test phase

\begin{tabular}{|c|c|c|c|c|c|}
\hline Phase & Test & $\begin{array}{l}\text { Specimens } \\
\text { details }\end{array}$ & $\begin{array}{l}\text { Level of } \\
\text { decay }{ }^{1), 2)}\end{array}$ & $\begin{array}{c}\text { Total } \\
\text { specimens }\end{array}$ & $\begin{array}{c}\text { Total } \\
\text { measurements }\end{array}$ \\
\hline \multirow{3}{*}{1} & $\begin{array}{c}\text { visual } \\
\text { inspection }\end{array}$ & $\begin{array}{l}20 \text { beams inspected } \\
\text { each } 40 \mathrm{~cm} \text { segment }\end{array}$ & all & 271 & 271 \\
\hline & \multirow{2}{*}{$\begin{array}{c}\text { impact } \\
\text { penetration }\end{array}$} & \multirow{2}{*}{$\begin{array}{l}20 \text { beams inspected } \\
\text { each } 40 \mathrm{~cm} \text { segment }\end{array}$} & $\begin{array}{c}\text { no visible } \\
\text { decay }\end{array}$ & 61 & 305 \\
\hline & & & decayed & 182 & 910 \\
\hline \multirow{3}{*}{2} & $\begin{array}{c}\text { impact } \\
\text { penetration }\end{array}$ & $\begin{array}{l}\text { middle segment } \\
\text { (each } 40 \mathrm{~cm})\end{array}$ & reference & 322 & 1610 \\
\hline & \multirow{2}{*}{$\begin{array}{l}\text { drilling } \\
\text { resistance }\end{array}$} & $\begin{array}{l}\text { middle segment } \\
\text { (each } 40 \mathrm{~cm} \text { ) }\end{array}$ & reference & 322 & 322 \\
\hline & & $\begin{array}{c}\text { end segments (3 } \\
\text { sections) }\end{array}$ & decayed & 20 & 240 \\
\hline \multirow{4}{*}{3} & \multirow[t]{2}{*}{ ultra-sound } & $\begin{array}{c}\text { middle segment ( } 3 \\
\text { specimens/beam) }\end{array}$ & reference & 60 & 120 \\
\hline & & end segments & decayed & 20 & 40 \\
\hline & \multirow{2}{*}{$\begin{array}{l}\text { compression } \\
\text { parallel to grain }\end{array}$} & $\begin{array}{c}\text { middle segment ( } 3 \\
\text { specimens/beam) }\end{array}$ & reference & 60 & 60 \\
\hline & & end segments & decayed & 20 & 20 \\
\hline
\end{tabular}

\footnotetext{
1) the term "all" indicates that the test was made to any level of decay.

2) the term "reference" indicates that the specimens were taken from the outer region of the cross section of the middle segments after removing the external decayed layer.
}

\subsection{Visual inspection and definition of critical sections}

Visual inspection is one of the most important steps in structural diagnosis. Using proper methods it is possible to document and classify a specific type of damage according to its extent and severity. This information is important to assess the global state of conservation of a timber element and also to analyze the variation found within a same element or group of elements. Furthermore, norms UNI 11035-2:2003 and UNI 11119:2004 also propose indicative values for visual strength grading, even if they can be conservative. Here, the old chestnut beams were 
visually inspected using the Italian norm UNI 11119:2004 and critical sections were considered depending on the applied stresses combined with defects distribution and quantity, which for the case of timber floor beams, typically in bending, correspond to the most bent and stressed sections. With regard to the presence of decay, also significant cross sections were identified and classified according to higher level of visible decay. This norm considers three classes (I, II and III) for strength grading of a single element, regarding onsite diagnosis for a given wood species (Table 3). A wood element corresponds to a given class if it fulfills all the imposed requirements and is considered as non-classifiable if it does not fit in any class. In this case, no mechanical parameters are proposed.

Table 3: Mechanical properties for chestnut (Castanea Sativa Mill.) using visual strength grading (UNI 11119:2004)

\begin{tabular}{ccccccc}
\hline \multicolumn{7}{c}{ Strength and stiffness properties $\left(\mathrm{N} / \mathrm{mm}^{2}\right)$} \\
Class & \multicolumn{2}{c}{$\begin{array}{c}\text { compression } \\
\text { // to grain }\end{array}$} & $\begin{array}{c}\perp \text { to grain } \\
\text { tension } \\
\text { bending } \\
\text { grain }{ }^{1)}\end{array}$ & $\begin{array}{c}\text { shear // } \\
\text { to grain }\end{array}$ & $\begin{array}{c}\text { MoE in } \\
\text { bending }\end{array}$ \\
\hline & 11 & 2.0 & 12 & 11 & 0.8 & 10000 \\
I & 9 & 2.0 & 10 & 9 & 0.7 & 9000 \\
II & 7 & 2.0 & 8 & 6 & 0.6 & 8000 \\
III & 7 & & & & & \\
& &
\end{tabular}

For the purpose of characterization of sections weakened by decay, the significant sections were considered to be the ending parts of the beams, since those segments revealed the most severe state of decay due to biological attack by insects and fungi. The extent of decay, either depth or length, is not uniform between beams. The segments of the beams where a high level and extent of decay was found combined with significant defects, were graded as non-classifiable, due to the consideration of a residual cross section accounting only for the non-decayed area. Assuming the proposed indicative values proposed by UNI 11119:2004 for the lower grade class (III), a decrease larger than $36 \%$ for the strength in compression parallel to the grain is expected for the decayed segments in comparison to the reference values (class I), as given in Table 3.

\section{EXPERIMENTAL RESULTS}

\subsection{Impact penetration tests}

For the impact penetration test, a Pilodyn $6 \mathrm{~J}$ device was used, that through the release of a spring, transforms the elastic potential energy into impact energy. The penetration of a metallic 
needle with $2.5 \mathrm{~mm}$ of diameter can be measured and the depth is inversely proportional to the density of the wood, which allows measuring surface fungi deterioration (Görlacher, 1987). Measurements were done along the entire length of the beams, including the most decayed regions (end parts), the middle segments (with lower percentage of visible decay) and in the sound reference samples (sawn wood with removal of exterior decay layer) (Table 4).

Table 4: Impact penetration test results

\begin{tabular}{ccccc}
\hline \multirow{2}{*}{ Segments } & \multicolumn{5}{c}{ Penetration depth $(d$ in $\mathrm{mm})$} \\
& minimum maximum & mean & $\mathrm{CoV}(\%)$ \\
\hline Old beams: endings & 6 & 22 & 12.16 & 14.7 \\
Old beams: middle & 6 & 16 & 11.05 & 16.3 \\
Reference specimens & 5 & 15 & 8.31 & 14.5 \\
\hline
\end{tabular}

The results obtained show that the difference between visibly decayed segments and other regions of the old beams is $1.11 \mathrm{~mm}$ in depth, which means that, in this case, the external decayed layer is rather small. With respect to the reference values, a difference of $3.85 \mathrm{~mm}$ is found, representing an increase of penetration depth of $32 \%$ between reference values (sawn wood) and sections with visible decay. Assuming these measurements, a multi-layer stratified cross section may be considered for the different segments of the beam regarding its decay visual inspection (Figure 2). This approach allows assessing different stages of decay evolution by visual inspection, and associating different mechanical properties to each layer. The $\mathrm{CoV}$ between different segments presented similar values varying from 14.5 to $16.3 \%$. Also a comparison was made to decayed and reference values within the same beam, finding a mean increase of penetration depth of $36 \%$ (with $\mathrm{CoV}=16.2 \%$ ). Besides decay, the difference of penetration depth is also explained by distinct percentages of sapwood and heartwood. The studied values are representative of the decay level because the impact penetration tests were made along the whole perimeter of the cross sections measuring several sections with different percentages of sapwood and heartwood.

The impact penetration tests were useful to detect different levels of decay depth by comparison between measurements along the length of each beam and the reference (non-decayed) specimens. Its on-site usefulness resides in the possibility to qualitatively differentiate between regions with different decay levels, even if measurements of reference specimens (non-decayed with similar percentage of sapwood and heartwood) are necessary to estimate the depth of decay. Also, it should be noted that these tests mainly evaluate the superficial layers of the elements and other typology of testing might be required to assess the characteristics of the inner core of the element. 


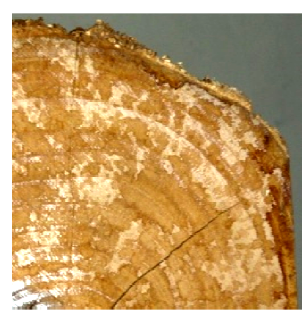

a)

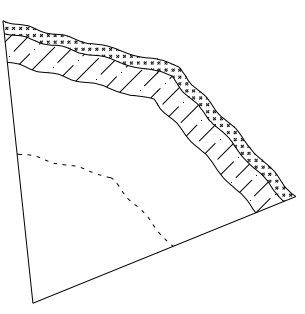

b)

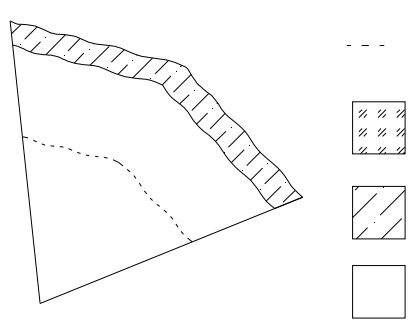

c) mean impact penetration limit

external decayed layer

lower resistant transition wood

non-decayed wood

Figure 2: Stratification of a cross section with decay: a) example of study; b) section with visible external decayed layer (ending of beams); c) section with no visible external decayed layer (middle segments of beams)

\subsection{Drilling resistance tests}

In order to assess the severity of decay in the critical sections, a Resistograph ${ }^{\circledR} 3450$ equipment was used. This is commercial testing equipment based on micro-drilling wood at constant speed, and measuring the required energy. It is usually adopted to obtain density profiles and allows characterizing the full size of the specimen (Rinn and Schweingruber, 1996). An example of a drilling resistance profile is presented in Figure 3, where the horizontal axis of the profile measures the length of the drilling path and the vertical axis provides the power consumption of the device as a measure of drilling resistance. The result of a drilling resistance test can be taken by the resistographic measure $(R M)$ given by the integral of the area beneath the resistance profile with respect to the length of drilling path, $h$ (eq. 1).

$$
R M=\frac{\int_{0}^{h} \text { Area }}{h}
$$

The used equipment model has a drilling needle with $3 \mathrm{~mm}$ diameter at the cutter of the drill bit and $1.5 \mathrm{~mm}$ diameter along the shank. The bit advances at a constant speed of $30 \mathrm{~cm} / \mathrm{min}$, turning at $1500 \mathrm{rpm}$. The profiles obtained by the drilling resistance equipment were analyzed, accounting to each initial measurement (needle entry) and last measurement (needle exiting) in the timber elements, as to minimize the effect of possible lateral friction. Measurements deviating from the expected straight path more than 5\% of the path length were not considered, and the measurement was repeated. These actions were feasible since access to both analyzed surfaces was possible. Drilling resistance tests were made in the sections that exhibited higher superficial decay but had not suffered severe cross section reduction. The tests were performed in the ending parts of the beams (segments that presented lower visual grading) in a section that still presented a defined cross section, obtaining values of $R M_{\text {decay. }}$ The mean value of $R M_{\text {decay }}$ was compared to the results of drilling resistance tests made to the reference values $R M_{\text {reference }}$ 
and a decrease of $19.4 \%$ was found from the reference to the decayed specimens. The reference specimens (non-decayed) presented a mean $R M$ of $304 \mathrm{bit}$, while the decayed specimens presented a mean $R M$ of 245 bit. Also the variation and dispersion of results was significantly different between samples, as the $\mathrm{CoV}$ for decayed specimens (with $\mathrm{CoV}=22.6 \%$ ) was approximately the double of the $\mathrm{CoV}$ of the reference sample (with $\mathrm{CoV}=10.4 \%$ ). Significant voids or lower resistant sections in the inner regions of the cross section were not found in the drilling resistance tests for the decayed specimens.

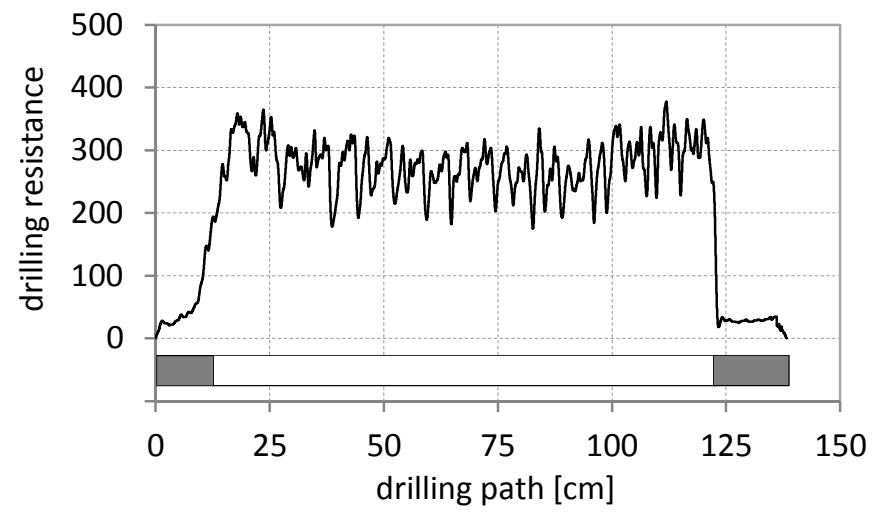

a)

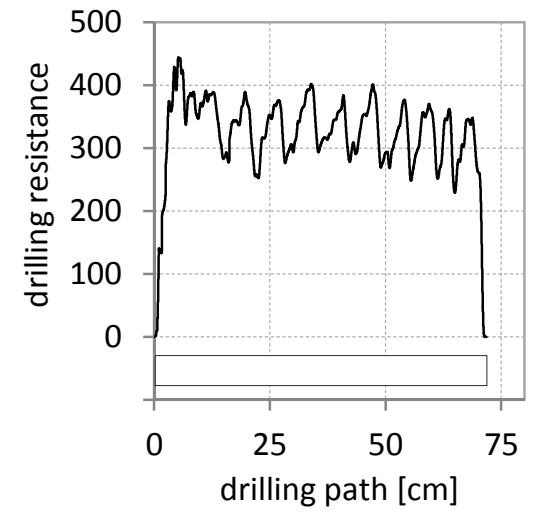

b)

Figure 3: Example of drilling resistance profile, with grey scale for visible decayed length, in:

a) decayed region at the end part of a beam; b) non-decayed section.

Drilling resistance tests were useful to estimate the depth of the decayed layer, even if it should be noted that the measurements are made regarding only the drilling path of the device needle, and therefore only evaluate the material locally. Its on-site usefulness might be low for elements with larger thickness due to the increase of lateral friction of the needle and possible deviation of the drilling path. Also, full on-site access to both parallel sides of an existing element may be not possible.

\subsection{Ultra-sound tests}

The ultra-sound tests were made with a Pundit Lab equipment with $54 \mathrm{kHz}$ frequency transmission transducers. The samples had a square cross section with $4 \mathrm{~cm}$ width and a length of $24 \mathrm{~cm}$. The samples were taken from the ending parts of the beams with signs of decay and from the reference segments at middle span of the beams. In case of superficial decay, specimens were taken from the outer regions of the cross sections. To provide a better comparison between samples with and without decay, regions with smaller depths of decay were selected. After removal of the external decay surface, the non-decayed specimens were also removed from the outer region of the cross sections. As a proper contact of the sample with 
the equipment probes was not possible on the lateral faces due to the superficial decay, only direct measurements along the grain were considered. For each sample, two measurements were taken and averaged, as a rule. If the two first measurements differed more than $5 \%$ then an additional third measurement would be taken and the average would be done with the three measurements. The propagation velocity decreased $2.11 \%$ in the decayed samples regarding all reference samples of the 20 beams (Table 5). The results evidenced that direct ultra-sound measurements (parallel to the grain measurements with $24 \mathrm{~cm}$ distance between probes) did not produce relevant differences in the propagation velocity regarding specimens with superficial decay, as expected. The minor difference found between values is mainly due to similar transmission paths made by the ultra-sound pulse waves. In this measurement configuration, the ultra-sound pulse was transmitted between probes essentially by clear wood with only a small attenuation due to the superficial decay layer found in the lateral faces.

Table 5: Direct ultra-sound test results relative to propagation velocity

\begin{tabular}{ccccccc}
\hline $\begin{array}{c}\text { Samples } \\
\left(4 \times 4 \times 24 \mathrm{~cm}^{3}\right)\end{array}$ & \multicolumn{5}{c}{ Propagation velocity $\left(v_{\mathrm{p}}\right.$ in $\left.\mathrm{m} / \mathrm{s}\right)$} \\
minimum maximum & mean & $\begin{array}{c}\mathrm{CoV} \\
(\%)\end{array}$ \\
\hline Decayed & 4569 & 5651 & 5109 & 6.5 & & \\
Non-decayed (reference values) & 4725 & 5627 & 5219 & 3.7 & & \\
\hline
\end{tabular}

${ }^{1)}$ samples were collected from the outer regions of the cross sections

The propagation velocity may be related to the static and dynamic moduli of elasticity $\left(E_{\text {sta }}\right.$ and $\left.E_{\mathrm{dyn}}\right)$ if the density of the timber element is known (eq. 2) (US Forest Products Laboratory, 1999).

$$
E_{\mathrm{sta}}=K \cdot E_{\mathrm{dyn}}=K \cdot v_{\mathrm{p}}^{2} \cdot \rho
$$

where $K$ is the proportionality constant depending on the wood species, $v_{\mathrm{p}}$ is the propagation velocity and $\rho$ is the wood density.

For practical purposes, the relation between $E_{\mathrm{sta}}$ and $E_{\mathrm{dyn}}$ is relevant $\left(E_{\mathrm{dyn}} \geq 0.90 E_{\mathrm{sta}}\right)$ and this relation is explained by the viscous-elastic behavior of wood (Bonamini et al., 2001). Density was determined for the reference samples by ISO 3131:1975 obtaining a mean value of $571.2 \mathrm{~kg} / \mathrm{m}^{3}(\mathrm{CoV}=7.9 \%)$. Although, density is likely to be lower in the decayed regions due to the loss of cellular wall destroyed by decay agents, its exact determination by standard methods is not feasible. Therefore, considering the same density for both decayed and non-decayed regions, a decrease of $3.9 \%$ in $E_{\mathrm{dyn}}$ for decayed regions, with respect to the reference values, 
was obtained. With the expected decrease for density in the decayed segments, this reduction would be higher.

Ultra-sound tests allowed detecting a decrease in propagation velocity for decayed specimens compared to the non-decayed, evidencing the loss of wood mass for decayed specimens, even if they did not produce information about the depth of decay. For the selected equipment, the probes could not provide an adequate contact to decayed surfaces and, therefore, were not suited to on-site assessment. Point contact probes, such as exponential probes, are better suited for onsite assessment regarding ultra-sound measurements on decayed or rough surfaces.

\subsection{Compression parallel to grain tests}

Tests for compression parallel to grain were made using EN 408:2003 with samples of $4 \times 4 \mathrm{~cm}^{2}$ cross section and $24 \mathrm{~cm}$ height (six times the smallest cross section dimension). Deformation was measured over a central gauge length of $16 \mathrm{~cm}$ (four times the smallest cross section dimension), using one pair of LVDTs (range $\pm 12.5 \mathrm{~mm}$ ), placed on opposite faces to take into account the effect of possible distortion. Compression parallel to grain strength $f_{\mathrm{c}, 0}$ and elastic modulus in compression $E_{\mathrm{c}, 0}$ were obtained by eq. 3 and 4 .

$$
E_{\mathrm{c}, 0}=\frac{l_{1} \cdot\left(F_{2}-F_{1}\right)}{A \cdot\left(w_{2}-w_{1}\right)}
$$

where $\left(F_{2}-F_{1}\right)$ is the increment of load $(\mathrm{N})$ on the straight line portion of the load deformation curve, $\left(w_{2}-w_{1}\right)$ is the increment of deformation ( $\left.\mathrm{mm}\right)$ corresponding to $\left(F_{2}-F_{1}\right), A$ is the cross section area $\left(\mathrm{mm}^{2}\right)$ and $l_{1}$ is the gauge length $(\mathrm{mm})$ for the determination of $E_{\mathrm{c}, 0}\left(\mathrm{~N} / \mathrm{mm}^{2}\right)$.

$$
f_{\mathrm{c}, 0}=\frac{F_{\max }}{A}
$$

where $F_{\max }$ is the maximum load applied (N).

For non-decayed specimens, the value of $A$ was calculated as the average value of two measurements by an electronic caliper, taken at a distance larger than $50 \mathrm{~mm}$ from the ends of the samples. The value of $A$ for decayed specimens was obtained by image processing (Figure 4) of two sections cut within $l_{1}$, to obtain $E_{\mathrm{c}, 0 \text {,decay }}$ (eq. 3 ), and of a section cut near the failure section of each specimen, to obtain $f_{\mathrm{c}, 0 \text {,decay }}$ (eq. 4). Specimens with decay were taken from specific beams, attending to the level of decay, and comparison with non-decayed sample was made only regarding non-decayed specimens from those beams. 


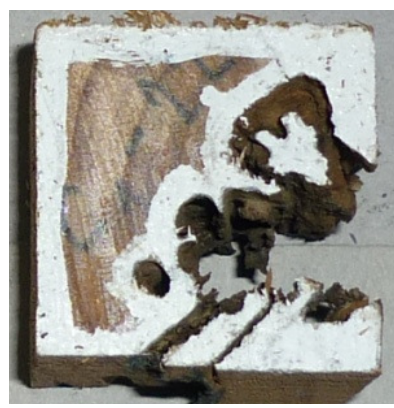

a)

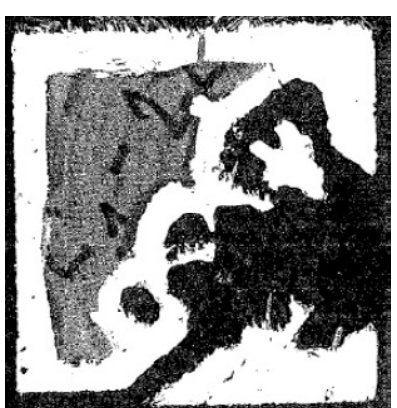

b)

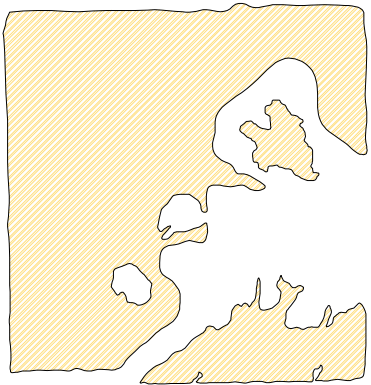

c)

Figure 4: Image processing for cross sectional area determination: a) example of decayed cross section, b) scanned cross section; c) computerized cross section drawing

The results of the compression parallel to grain tests (Table 6) evidenced that the decayed samples present a decrease of $33.1 \%$ for $f_{\mathrm{c}, 0}$ and $6.2 \%$ for $E_{\mathrm{c}, 0}$. A similar value of decrease (36\%) is found when reducing from class I to class III in visual grading (UNI 11119:2004) (see Table 3) for the compressive strength parallel to the grain. In terms of stiffness values, the mean values for the experimental campaign are higher than those considered for the bending modulus of elasticity indicated for class I. The variation of results for decayed samples is significantly higher than for the reference specimens. A significant decrease is found for $f_{\mathrm{c}, 0}$ which might be due to buckling instability in consequence of the increase of slenderness resulting from the reduction of effective cross section. The loss of cross section due to decay must be considered for buckling limit state verification. The decayed area, although with lower compressive strength, stills provides some level of confinement to the non-decayed fibers and, thus, must be considered partially in the residual cross section (Lourenço et al., 2013).

Table 6: Compression parallel to grain test results

\begin{tabular}{cccccc}
\hline \multirow{2}{*}{$\begin{array}{c}\text { Samples } \\
\left(4 \times 4 \times 24 \mathrm{~cm}^{3}\right)\end{array}$} & & \multicolumn{5}{c}{ Compression // grain $\left(\mathrm{N} / \mathrm{mm}^{2}\right)$} \\
& & minimum maximum & mean & $\begin{array}{c}\mathrm{CoV} \\
(\%)\end{array}$ \\
Decayed & $E_{\mathrm{c}, 0 \text {,decay }}$ & 2566 & 36840 & 11840 & 64.2 \\
& $f_{\mathrm{c}, 0 \text {,decay }}$ & 12.40 & 49.90 & 28.75 & 35.0 \\
\cline { 2 - 6 } $\begin{array}{c}\text { Non-decayed (reference } \\
\text { values) }\end{array}$ & $E_{\mathrm{c}, 0 \text {,undecay }}$ & 6685 & 16500 & 12620 & 15.7 \\
& $f_{\mathrm{c}, 0 \text {,undecay }}$ & 24.96 & 58.82 & 42.99 & 17.2 \\
\hline
\end{tabular}

1) samples were collected from the outer regions of the cross sections

\subsection{Test results and dispersion of values}

The results of the different test phases are presented in the form of box plots for better definition of the dispersion of values regarding the different quartiles (Figure 5). Outliers are also 
considered, with the minimum and maximum limits for non-outlier values defined by the distance of 1.5 times the inter-quartile range.

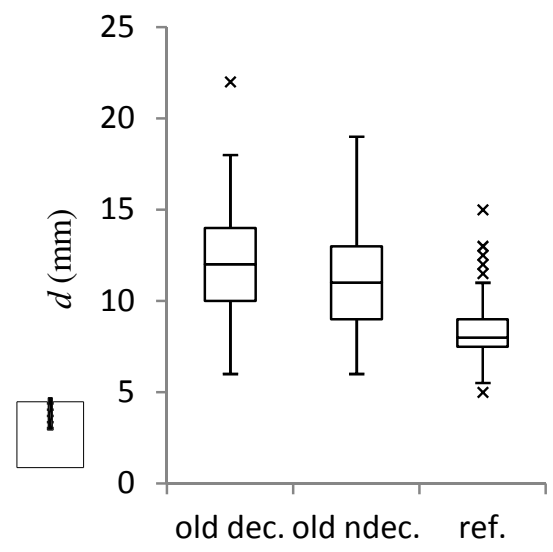

a)

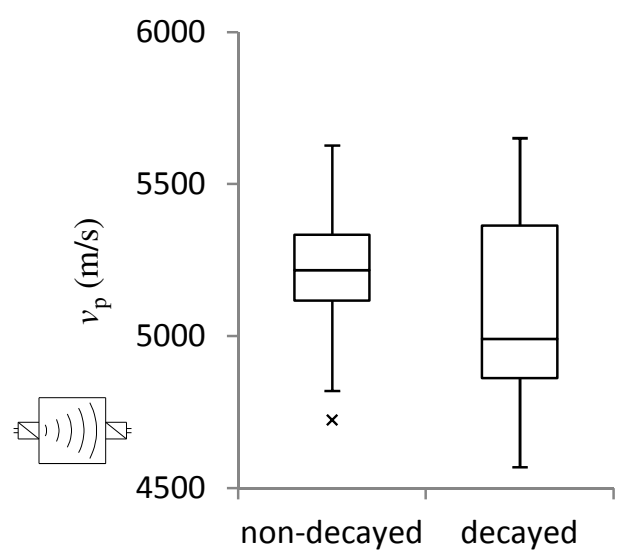

c)

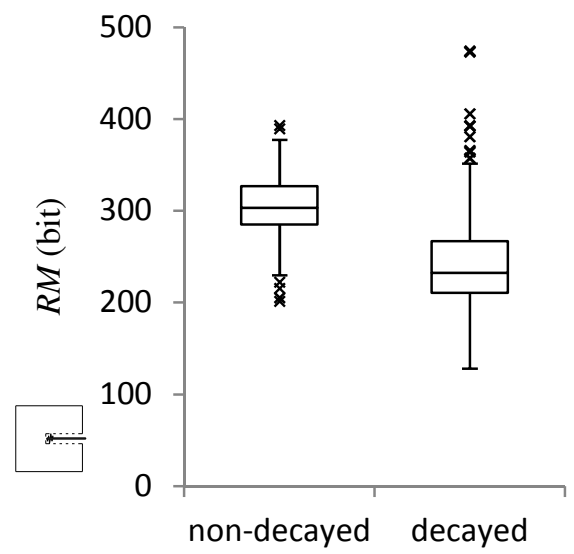

b)

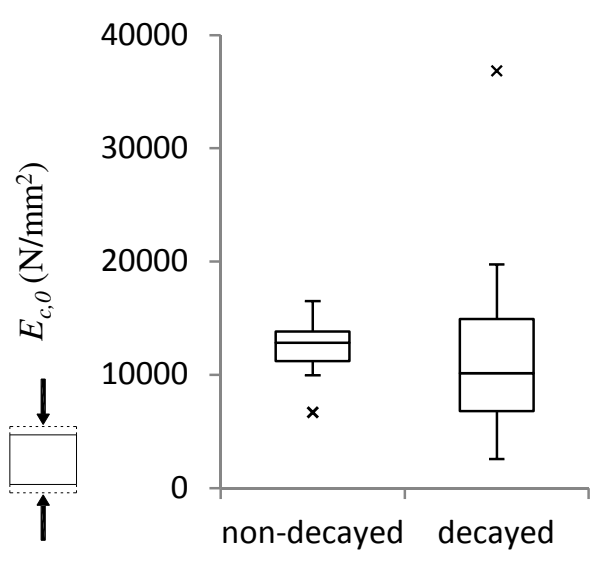

d)

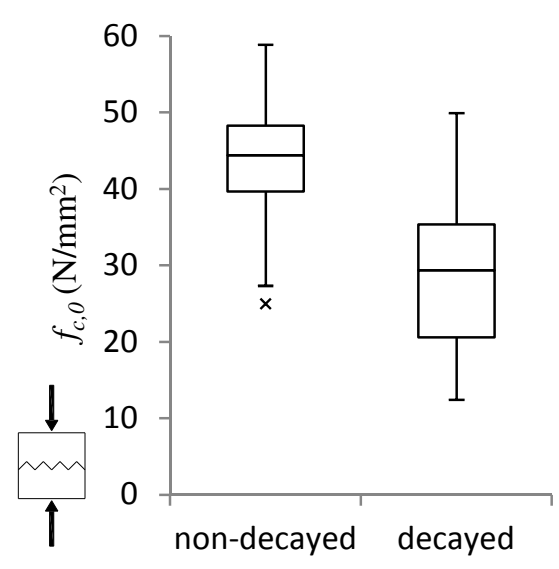

e)

Figure 5: Box plots of test results for non-decayed (reference) and decayed samples in: a) impact penetration; b) drilling resistance; c) ultra-sound; d) and e) compression parallel to grain 
For the penetration resistance tests, lower median depths represent samples with lower percentage of decay. This decrease in penetration depth from old decayed samples, through old samples with no visible decay and finally to reference samples without decay, is consistent with the decrease of resistance related to different stages of decay. In this study, these stages were considered in correspondence with the model described in Figure 2. The remaining nondestructive tests also evidenced lower values of the resistance indicators for decayed samples, with higher dispersion between upper and lower quartiles and between extreme values, resulting in higher coefficients of variation for decayed samples. The mechanical tests evidenced similar behavior to the non-destructive tests, with higher dispersion and lower median values for the decayed samples, both for stiffness and strength parallel to the grain. In both cases, lower outliers were mainly found for non-decayed samples where higher values are expected, whereas upper outliers were mainly found for decayed samples where lower median values are expected.

\section{DECAY MODEL AND PARAMETER CALIBRATION}

\subsection{Decay models}

After a decay process is initiated, its evolution depends mainly on wood moisture and temperature conditions (Zabel and Morrell, 1992). The evolution of decay along time has been studied regarding the possibility of using models that may predict timber performance in a quantitative and probabilistic format (Leicester, 2001 and Leicester et al. 2009). On those models, it is assumed that non-decayed wood suffers no strength loss and that the transition zone is a narrow band, that can be lumped on a decay front along the longitudinal axis of the structural members and within the cross section (Figure 6a). The decay models are assumed as bi-parametrical idealized models given by a bilinear function (Figure 6b). The two parameters are $t_{\mathrm{lag}}$ (year) corresponding to the time before noticeable decay commences and $r$ (mm/year) corresponding to an annual decay penetration rate depending on climate, durability and structural conditions of the timber element. For the case of Australian climate commonly used wood species and for timber elements directly exposed to the weather conditions, these parameters are given by (eq. 5 and 6) (Leicester et al., 2009):

$$
\begin{gathered}
t_{\text {lag }}=8.5 \cdot r^{-0.85} \\
r=k_{\text {climate }} \cdot k_{\text {wood }} \cdot k_{\mathrm{t}} \cdot k_{\mathrm{w}} \cdot k_{\mathrm{n}} \cdot k_{\mathrm{g}} \cdot k_{\mathrm{p}}
\end{gathered}
$$

where $k_{\text {climate }}$ is a climate parameter, $k_{\text {wood }}$ is a wood durability parameter, $k_{\mathrm{t}}$ is a thickness parameter, $k_{\mathrm{w}}$ is a width parameter, $k_{\mathrm{n}}$ is a connector parameter, $k_{\mathrm{g}}$ is a geometry parameter and 
$k_{\mathrm{p}}$ is a paint parameter. For in-ground timber elements, the decay model parameters are given by (eq. 7 and 8) (Wang et al., 2008):

$$
\begin{gathered}
t_{\text {lag }}=3 \cdot r_{\text {ingr }}{ }^{-0.4} \\
r_{\text {ingr }}=k_{\text {climate_ingr }} \cdot k_{\text {wood_ingr }}
\end{gathered}
$$

where $k_{\text {climate_ingr }}$ is a climate parameter, $k_{\text {wood_ingr }}$ is a wood durability parameter and $r_{\text {ingr }}(\mathrm{mm} /$ year) corresponds to the annual decay penetration rate.

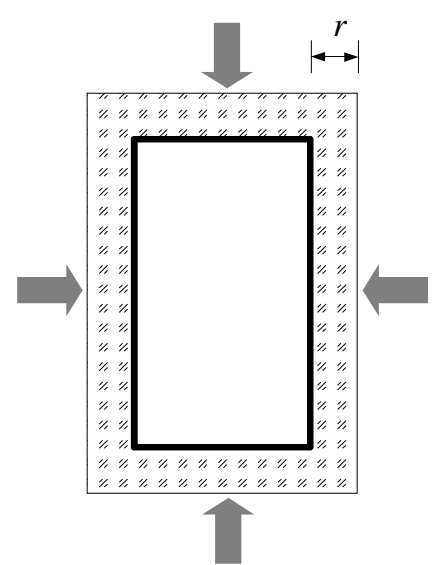

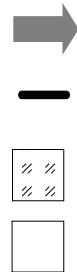

a)

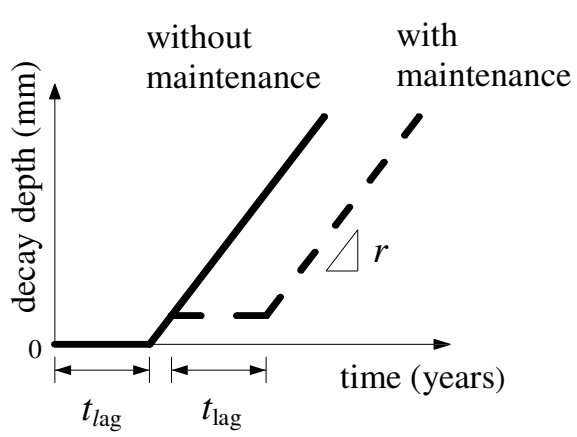

b)

Figure 6: Progress of decay: a) damage penetration (cross section); b) idealized model. Adapted from Leicester (2001)

Annual decay penetration rates calibrated with existing pine timber members above ground, using in-situ inspection and non-destructive testing, are given in Brites et al. (2013) and Lourenço et al. (2013), for timber elements in similar climatic conditions to the members considered in the present work. Here, to assess the decay progress in the timber members, it was assumed that decay was regularly spread along the perimeter of the cross section progressing to the core of the element.

\subsection{Decay modeling results}

The load bearing capacity of a decayed cross section depends on the residual cross section area given by the non-decayed region, and thus the loss of load bearing capacity of the element is inevitable due to the loss of cross section area. The possibility that a decayed area could still collaborate for the load bearing capacity of the element has been addressed in Lourenço et al (2013) for a case study. A larger or smaller variation on the mechanical properties of timber due 
to decay depends on its stage of development and extent. Thus, it is important to predict the evolution of decay along time in order to define when a limit residual cross section is obtained. To obtain indicative values for $r$ (annual decay penetration rate) and $t_{\text {lag }}$ (time before noticeable decay commences), the previous referenced decay models were considered.

The decay model parameters were calculated for the end part of the chestnut timber beams, which were in contact with the masonry walls, considering the proposed model for exposed timber elements (Leicester et al., 2009), assuming a temperate environment. However, calibration of the model parameters is required because the timber members under consideration are sheltered and, therefore, not expected to be exposed to sudden climatic changes. As the ends of the beams were embedded in the masonry walls, the estimation of the decay parameters also followed the in-ground decay model (Wang et al., 2008), with analogous input for climate and wood durability class as considered for the above ground model. It is noted that the in-ground decay model by Wang et al. (2008) was developed for vertical timber elements embedded in ground. Therefore, the main moisture inducing parameter is water percolation in the surrounding soil derived from precipitation, which is not applicable for the ends of beams embedded in granite walls, where moisture occurs from different sources of structural dampness. The results of the estimations are compiled in Table 7. The values proposed in Brites et al. (2013) and Lourenço et al. (2013) are also mentioned in Table 7, since they provide information about case studies with similar location, climate and lifetime period, although different wood species.

Table 7: Estimated decay model parameters assuming different exposures and case studies

\begin{tabular}{|c|c|c|c|c|}
\hline \multicolumn{2}{|c|}{ Model application } & $r(\mathrm{~mm} / \mathrm{year})$ & $t_{\text {lag }}($ years $)$ & Wood type \\
\hline \multicolumn{2}{|c|}{$\begin{array}{l}\text { Exposed timber (Leicester et al. } \\
\text { 2009) }\end{array}$} & 0.325 & 22.1 & $\begin{array}{c}\text { Durability class } 1 \text { - outer } \\
\text { heartwood }\end{array}$ \\
\hline \multicolumn{2}{|c|}{$\begin{array}{l}\text { In-ground decay (Wang et al. } \\
\text { 2008) }\end{array}$} & 0.248 & 5.2 & $\begin{array}{c}\text { Durability class } 1 \text { - outer } \\
\text { heartwood }\end{array}$ \\
\hline \multirow{3}{*}{$\begin{array}{l}\text { Case study } \\
\text { (Brites et al. } \\
\text { 2013) }\end{array}$} & Top face & 0.237 & 10.8 & \multirow{3}{*}{ Pinus pinaster Ait. } \\
\hline & Bottom face & 0.119 & 19.4 & \\
\hline & Lateral faces & 0.079 & 27.3 & \\
\hline \multicolumn{2}{|c|}{$\begin{array}{l}\text { Case study (Lourenço et al. } \\
\text { 2013) }\end{array}$} & 0.075 & 8.5 & Pinus canariensis Sweet \\
\hline
\end{tabular}

Assuming the same period of time before visible decay commences, as given by the exposed timber decay model, but taking into account the decay depth present in the studied elements, a decay rate based on the experimental data was calculated. In this case, the decay depth was assumed by accounting the difference between the area of sections without visible decay and the 
decayed sections in the old beams, and accounting for the penetration depth difference given by the impact penetration tests, between old decayed sections and non-decayed reference samples. A mean penetration depth of $10.35 \mathrm{~mm}$ was found. The consideration of a 100 years lifetime would result in an experimental $r=0.13 \mathrm{~mm} /$ year, which is, as expected, considerably different than the predicted for either the exposed or in-ground models elements (Leicester et al. 2009 and Wang et al., 2008) since these models were developed for significantly different climate conditions (for the Australian context) and different moisture inducing processes. Therefore, the value is more similar to the models considered in case studies in Portugal, as they correspond to more similar climate and surrounding conditions (sheltered beams embedded in masonry walls) and structural dampness processes. Therefore, the main reason to this difference is the parameter related to the environmental conditions which was not calibrated for the local climatic conditions and type of climate exposure. Moreover, the models used for prediction of $r$ consider a large coefficient of variation for this parameter (reaching values above 100\%), which also accounts for the differences found in either the models corresponding to Australian (Leicester et al. 2009 and Wang et al., 2008) and the Portuguese (Brites et al. 2013 and Lourenço et al. 2013) contexts. The use of large coefficients of variation of decay rate of wood for the Australian context has also been addressed in Wang and Wang (2012).

\section{CONCLUSIONS}

Decay is usually present in existing timber structures, when environmental conditions are favorable to biological growth and no preventative actions have been taken to minimize it. Besides evidencing a poor visual condition, decayed sections have a reduced cross section, not only in terms of residual area but also in terms of effective strength and stiffness, even for early stages of decay. Therefore decay should be prevented and, when present, should be taken into consideration in the safety assessment.

In order to characterize the weak sections of old chestnut beams, an experimental campaign was made regarding non-destructive and destructive testing. Visual inspection and non-destructive tests were carried out in correspondence with the destructive tests and the reduction of strength and stiffness between decayed and non-decayed samples was similar in the different methods. The non-destructive tests were useful to differentiate between levels of decay and to assess its depth and extent. Impact penetration tests presented the closer decrease percentage, from nondecayed to decayed samples, comparing to the compression parallel to the grain destructive tests. Both strength and stiffness properties decreased for decayed sections, with a difference of $32.0 \%$ in impact penetration depth, $2.1 \%$ in propagation velocity (corresponding to $3.9 \%$ in dynamic modulus), $19.4 \%$ in drilling resistance, $33.1 \%$ for compression parallel to grain 
strength and $6.2 \%$ for the modulus of elasticity in compression parallel to grain. In all tests, the existence of decay resulted in larger dispersion of values, when compared to non-decayed sections. Also in terms of coefficient of variation and dispersion of values, the pin penetration tests presented closer results comparing to the compression parallel to the grain destructive tests. Therefore, this seems a valid method to estimate the change of the mechanical properties of timber subjected to decay mainly located in the outer layers of the elements.

A decay model was also considered and the observed annual decay penetration rate was found to be smaller than reported in the literature for exposed (Leicester et al. 2009) and for in-ground Wang et al., 2008) decay models for the Australian context, as this case study differed in the climatic exposure and moisture inducing process. The results (decay rate of $0.13 \mathrm{~mm} / \mathrm{year}$ ), were in better agreement with results obtained for other species in Portugal (Brites et al. 2013 and Lourenço et al. 2013), since more similar climate and surrounding conditions (sheltered beams embedded in masonry walls) and structural dampness processes were present. The diverse decay rates found using the different decay models evidenced the importance of calibrating the climate parameter and level of exposure to damp. Although, these models may allow for a better design and to provide indications about the preliminary timing for maintenance plans, a more efficient method to increase the durability of the structural element would be the consideration of adequate construction solutions and maintenance actions that would decrease the possibility of decay appearance. Increase of timber elements' durability is, therefore, better obtained by controlling the environment parameters (e.g. relative humidity, ventilation and temperature) so as to prevent favorable conditions for decay evolution.

\section{ACKNOWLEDGEMENTS}

The first author gratefully acknowledges the financial support of the Portuguese Science Foundation (Fundação para a Ciência e Tecnologia, FCT), through grant SFRH/BD/62326/2009.

\section{REFERENCES}

Beckmann, P., and Bowles, R. 2004. Structural Aspects of Building Conservation. 2nd ed. Elsevier Butterworth-Heinemann publications, Oxford.

Bonamini, G., Noferi, M., Togni, M., and Uzielli, L. 2001. Il Manuale del Legno Strutturale, Volume I, Ispezione e diagnosi in opera. Mancosu Editore, Rome.

Brites, R. D., Neves, L. C., Machado, J. S., Lourenço, P. B., and Sousa, H. S. 2013. Reliability analysis of a timber truss system subjected to decay. Engineering Structures. 46: 184192. 
Bucur, V., Garros, S., Navarrete, A., Troya, M.T., and Guyonnet, R. 1997 Kinetics of wood degradation by fungi with $\mathrm{x}$-ray microdensitometric technique. Wood Science and Technology. 31:383-389.

Carll, C. G., and Highley, T. L. 1999. Decay of Wood and Wood-Based Products Above Ground in Buildings. Journal of Testing and Evaluation. 27(2): 150-158.

EN 408. 2003. Structural Timber and Glued Laminated Timber. Determination of Some Physical and Mechanical Properties. CEN.

Görlacher, R. 1987. Non destructive testing of wood: an in-situ method for determination of density. Holz as Roh-und Werkstoff. 45: 273-278.

ISO 3131. 1975. Wood - Determination of density for physical and mechanical tests. ISO.

Leicester, R. H. 2001. Engineered durability for timber construction. Progress in Structural Engineering and Materials. 3(3): 216-227.

Leicester, R. H., Wang, C-H., Nguyen, M. N., and MacKenzie, C. E. 2009. Design of Exposed Timber Structures. Australian Journal of Structural Engineering. 9(3): 241-248.

Lourenço, P. B., Feio, A. O., and Machado, J. S. 2007. Chestnut wood in compression perpendicular to the grain: Non-destructive correlations for results in new and old wood. Construction and Building Materials. 21: 1617-1627.

Lourenço, P. B., Sousa, H. S., Brites, R. D., and Neves, L. C. 2013. In situ measured cross section geometry of old timber structures and its influence on structural safety. Materials and Structures. DOI: 10.1617/s11527-012-9964-5.

Macchioni, N., Brunetti, M., Pizzo, B., Burato, P., Nocetti, M., Palanti, S. 2012. The timber structures in the Church of the Nativity in Bethlehem: Typologies and diagnosis. Journal of Cultural Heritage. 13:e42-e53.

Macchioni, N., Palanti, S., and Rozenberg, P. 2007. Measurements of fungal wood decay on Scots pine and beech by means of X-ray microdensitometry. Wood Science and Technology. 41:417-426. DOI: 10.1007/s00226-007-0128-7.

Rinn, F., and Schweingruber, F. 1996. Resistograph and x-ray density charts of wood comparative evaluation of drill resistance profiles and $\mathrm{x}$-ray density charts of different wood species. International Journal of the Biology, Chemistry, Physics and Technology of Wood. 50: 303-311.

Ross, R. J., Brashaw, B. K., Wang, X., White, R. H., and Pellerin, R.F. 2004. Wood and Timber: Condition Assessment Manual. Forest Products Society, Madison, Wisconsin.

Stalnaker, J. J., and Harris, E. C. 2002. Structural Design in Wood. 2nd ed. Kluwer Academic Publishers, Boston. 
Trotman, T., Sanders, C., and Harrison, H. 2004. Understanding Dampness - BR466. IHS BRE Press. United Kingdom. ISBN: 9781860816864

UNI 11035-2. 2003.Visual strength grading rules and characteristic values for Italian structural timber population. ENIU.

UNI 11119. 2004. On site inspections for the diagnosis of timber members. ENIU.

US Forest Products Laboratory. 1999. Wood Handbook - Wood as an Engineering Material. US Department of Agriculture, Forest Service, Forest Products Laboratory. Madison.

Viitanen, H., and Ritschkoff, A. 1991. Brown rot decay in wooden constructions - effect of temperature, humidity and moisture. Rep. n222. Swedish University of Agricultural Sciences.

Wang, C-H., Leicester, R. H., and Nguyen, M. N. 2008. Probabilistic procedure for design of untreated timber poles in-ground under attack of decay fungi. Reliability Engineering \& System Safety. 93: 476-481.

Wang, C-H., and Wang, X. 2012. Vulnerability of timber in ground contact to fungal decay under climate change. Climatic Change. 115:777-794. DOI: 10.1007/s10584-0120454-0.

Wilcox, W. 1968. Changes in Wood Microstructure Trough Progressive Stages of Decay. USDA Forest Service Research Paper FPL-70.

Wilcox, W. 1978. Review of Literature on the Effects of Early Stages of Decay on Wood Strength. Wood and Fiber. 9(4): 252-257.

Yang, J. L., Wardlaw, T., and Scott, L. 2000. Density and strength characteristics of discoloured and decayed regrowth eucalypts - a preliminary study. Australian Forestry. 63: 188193.

Zabel, R. A., and Morrell, J. J. 1992. Wood Microbiology - Decay and its Prevention. New York: Academic Press. 